\title{
MENINGKATKAN PROFESIONALITAS GURU DI ERA MASYARAKAT EKONOMI ASEAN (MEA) DI YAYASAN PERGURUAN ALMA'SHUM SIDODADI KABUPATEN ASAHAN
}

\author{
Uswatun Hasanah $^{1}$ Zulfi Azhar ${ }^{2}$ \\ 1,2 Sistem Informasi STMIK Royal Kisaran
}

\begin{abstract}
The challenges in the world of education today, especially in the Era of the Asean Economic Community (MEA) is quite heavy, where the world of education must be able to adjust to the current conditions. Starting from policy makers who have to think about breakthroughs in the form of rules up to the educational implementer who can immediately act to improve the learning process to fit the need for market share in this era of competition. Participants Community service activities conducted at the Alma'shum Perguruan Foundation Sidodadi Village District West Kisaran is the teachers who teach at the Foundation of Alma'shum College. The purpose of this activity Provide information and knowledge about the role of teachers in the era of ASEAN Economic Community and Provide Information and knowledge about the importance of technology mastery in facing global challenges. The team of lecturers who conduct this activity consists of lecturers who have different educational background. The result of this activity is the approval of the follow up activities to improve the competence of lecturers especially in the field of Information Technology.
\end{abstract}

Keywords: Profesionalism MEA, Competence, Teacher, TI

\begin{abstract}
Abstrak: Tantangan dalam dunia pendidikan saat ini terutama di Era Masyarakat Ekonomi Asean (MEA) cukup berat, dimana dunia pendidikan harus mampu menyesuaikan dengan kondisi saat ini. Mulai dari pembuat kebijakan yang harus memikirkan terobosan dalam bentuk aturan sampai dengan pelaksana pendidikan yang dengan segera bisa bertindak untuk memperbaiki proses pembelajaran agar sesuai dengan kebutuhan akan pangsa pasar di era persaingan seperti ini. Peserta Kegiatan pengabdian masyarakat yang dilakukan di Yayasan Perguruan Alma'shum Kelurahan Sidodadi Kecamatan Kisaran Barat ini adalah guru-guru yang mengajar di Yayasan Perguruan Alma'shum. Tujuan dari kegiatan ini Memberikan informasi dan pengetahuan tentang peranan guru dalam era Masyarakat Ekonomi Asean dan Memberikan Informasi dan pengetahuan tentang pentingnya penguasaan teknologi dalam menghadapi tantangan global. Tim dosen yang melakukan kegiatan ini terdiri dari dosen-dosen yang memiliki latar pendidikan yang berbeda. Hasil dari kegiatan ini adalah disepakatinya kegiatan lanjutan guna meningkatkan kompetensi dosen terutama di bidang Teknologi Informasi
\end{abstract}

Kata kunci: Profesionalitas, MEA, Kompetensi, Guru, TI

\section{PENDAHULUAN}

Tantangan dalam dunia pendidikan di Indonesia akan semakin kompleks. Terutama dengan pemberlakuan Masyarakat Ekonomi Asean
(MEA). Merupakan tantangan bagi dunia pendidikan kita dalam menghadapi liberalisasi pendidikan yang sudah mulai tampak terhadap pemberlakuan MEA (Masyarakat Ekonomi ASEAN) 2015, sepatutnya berbagai pihak yang terkait 
dalam bidang pendidikan memberi solusi untuk meningkatkan kualitas pendidikan Indonesia. Mulai dari pembuat kebijakan yang harus memikirkan terobosan dalam bentuk aturan sampai dengan pelaksana pendidikan yang dengan segera bisa bertindak untuk memperbaiki proses pembelajaran agar sesuai dengan kebutuhan akan pangsa pasar di era persaingan seperti ini. Pemberdayaan inilah yang akan menjadi sebuah kesatuan yang utuh dan benar-benar dibutuhkan untuk mencetak generasi pembelajar yang mampu berkompetisi.

Salah satu tenaga profesional yang bisa langsung berperan dalam perubahan nyata di dunia pendidikan adalah guru. Sudah jelas bahwa guru dituntut utnuk menjadi profesional agar mampu mengemban tugasnya secara maksimal. Untuk itu guru harus memiliki kompetensi yang wajib dipenuhi, yaitu kompetensi pedagogis, kompetensi kepribadian, kompetensi profesional, dan kompetensi sosial. Namun Profesionalisme guru yang belum optimal menjadi salah satu permasalahan dalam dunia pendidikan Indonesia. Tanggung jawab yang perlu dilakukan oleh guru terhadap hal tersebut salah satunya adalah dengan memilih dan menggunakan metode mengajar yang tepat untuk menghasilkan proses belajar mengajar yang lebih baik, efektif, dan efisien (Muchith, 2008). Dengan peningkatan profesionalisme guru, diharapkan lima tahun ke depan terjadi peningkatan mutu, relevansi, serta kompetensi dalam daya pikir dan daya saing yang bisa dilakukan oleh guru. Itulah bentuk nyata peran guru untuk bisa mensukseskan MEA yaitu dengan menjadi fasilitator bagi siswa agar sukses learning to know, learning to do, learning to become, dan learning to be together sebagai pondasi pendidikan yang berprinsip. Sehingga bisa disimpulkan bahwa peningkatan kompetensi guru bisa menjadi jawaban dalam persoalan tantangan di era global.

\section{METODE}

Metode pelaksanaan dalam kegiatan pengabdian masyarakat ini dilakukan dalam bentuk workshop di dalam kelas dengan menggunakan metode ceramah dan demonstrasi, diskusi dan diakhiri dengan tanya jawab. Dimulai jam 9 pagi sampai dengan jam 3 sore, materi diberikan oleh tim dosen yang memiliki disiplin ilmu yang berbeda.

\section{PEMBAHASAN}

Khalayak sasaran dalam kegiatan Pengabdian kepada Masyarakat ini adalah guru-guru Yayasan Perguruan Alma'shum Kelurahan Sidodadi Kecamatan Kisaran Barat Kabupaten Asahan. Materi yang diberikan diantaranya adalah: Kajian umum tentang Masyarakat Ekonomi Asean (MEA), Profesi Guru diantara peluang dan tantangan di Era MEA, Guru harus lahirkan generasi MEA, Kompetensi Guru di Era MEA Materi berikutnya Peningkatan Kompetensi TIK Bagi Guru

1. Masyarakat Ekonomi Asea

Masyarakat Ekonomi Asean tidak hanya membuka arus perdagangan barang atau jasa, tetapi juga pasar tenaga kerja profesional, seperti dokter, pengacara, akuntan, guru dan lainnya.

Staf Khusus Menteri Tenaga Kerja dan Transmigrasi, Dita Indah Sari, menjelaskan bahwa MEA mensyaratkan adanya penghapusan aturan-aturan yang sebelumnya menghalangi perekrutan tenaga kerja asing. MEA akan lebih membuka peluang tenaga kerja asing untuk mengisi berbagai jabatan di Indonesia

2. Profesi Guru diantara Peluang dan Tantangan dalam Era MEA

Tantangan yang harus di hadapi oleh guru pada saat sekarang ini adalah bagaimana kemampuan adaptasi dengan era global. Guru kita hari ini kebanyakan hidup dimasa lampau yang kemajuan 
Available online at http://jurnal.stmikroyal.ac.id/index.php/jurdimas

teknologi informasinya masih kurang jika dibandingkan dengan hari ini. Tentunya jika sudah seperti ini profesi guru di tuntut untuk keprofesionalismeannya. Guru yang profesional bukan hanya sekedar alat untuk transmisi kebudayaan tetapi mentranformasikan kebudayaan itu kearah budaya yang dinamis yang menuntut penguasaan ilmu pengetahuan, produktivitas yang tinggi, dan kualitas karya yang dapat bersaing. Dengan begitu guru bukan lagi menjadi robot pendidikan bagi peserta didik melainkan merupakan dinamisator yang mengantar potensipotensi peserta didik kepada kreativitas

- Guru Harus Lahirkan Generasi MEA

Generasi MEA akan lahir dari guru yang professional. Menjadi guru professional tentunya harus terus meningkatkan pengetahuan, wawasan dan skill untuk dapat menyesuaikan dengan kondisi saat ini dan kebutuhan pasar tenaga kerja mengatakan bahawa MEA menjadi sebuah wadah bagi tenaga pendidik untuk memfasilitasi siswa-siswa dalam menanamkan sedini mungkin tentang bagaimana menjadi pribadi yang tetap bisa survive dalam tuntutan global yang semakin tinggi. (Utari, Nyoman Sudana Degeng dan Sa'dun akbar, 2016)

- Kompetensi Guru di Era MEA

Menurut Mugara (2011) Salah satu indikator guru profesional dan kompeten adalah guru yang mampu beradaptasi dengan perkembangan keilmuan yang hari demi hari semakin canggih. Selain itu, guru yang profesional dan kompeten juga harus mampu menerapkan model dan metode pembelajaran berdasarkan tuntutan waktu dan kebutuhan peserta didik.

Mampuono Rasyidin Tomoredjo dalam Mugara (2011:3) menyatakan bahwa supaya guru menjadi profesional yang sesuai dengan era global dan digital ini hendaknya guru kurang lebih memiliki sembilan kriteria guru profesional sebagai berikut:

1. Mahir pada core competency-nya
2. Mengerti dan memahami kurikulum beserta aplikasi dan pengembangannya

3. Menguasai pedagogik secara teoritis dan praktis beserta pengembangannya

4. Menjadi pendengar yang baik dan empatik

5. Menguasai public speaking, terampil memotivasi dan menginspirasi

6. Menjadi pembaca yang efektif dan broad minded

7. Biasa melakukan riset dan penulisan

8. Bisa mengaplikasikan TIK berbasis pembelajaran

9. Menguasai bahasa internasional Menurut Surya (2015) Untuk menjadi guru di abad 21, guru harus :

1. Mengikuti berbagai perkembangan yang terjadi diluar ruangan kelas dan memperhatikan kondisi siswa

2. Belajar, berfikir, dan memimpin serta memberikan kesempatan bagi siswa untuk berfikir, membangun jawaban, mengembangkan rasa keingintahuan, memperluas kemungkinan.

3. Menjadi creator, innovator, pembangkit gagasan, petunjuk jalan, motivator dan fasitilatator

4. Memanfaatkan teknologi komunikasi dan informasi

5. Mengembangkan pola-pola pembelajaran abad 21 yang berpusat pada siswa, menantang, investasi, menilai secara kritis.

Untuk bisa melahirkan generasi

MEA, maka peningkatan profesionalitas guru menjadi kebutuhan utama, guru harus mampu menjadi pembaca yang efektif serta broad minded

3. Peningkatan Kompetensi TIK bagi Guru

Inggit Dyaning Wijayanti (2011) dalam Mugara (2011:4) memberikan Standar Kompetensi Guru yang harus dikuasai dalam penguasaan TIK adalah :

1. Mengoperasikan komputer personal dan periferalnya

2. Merakit, menginstalasi, menset-up, memelihara dan melacak serta memecahkan masalah 
Vol. 1, No. 2, Jul 2018, hlm. $69-74$

Available online at http://jurnal.stmikroyal.ac.id/index.php/jurdimas

(troubleshooting) pada komputer personal

3. Melakukan pemrograman komputer dengan salah satu bahasa pemrograman berorientasi objek

4. Mengolah kata ( word processing ) dengan komputer personal

5. Mengolah lembar kerja (spreadsheet) dan grafik dengan komputer personal

6. Mengelola pangkalan data (data base) dengan komputer personal atau komputer server

7. Membuat presentasi interaktif yang memenuhi kaidah komunikasi visual dan interpersonal.

Berikut adalah dokumentasi kegiatan pengabdian masyarakat di Perguruan Alma'shum adalah:

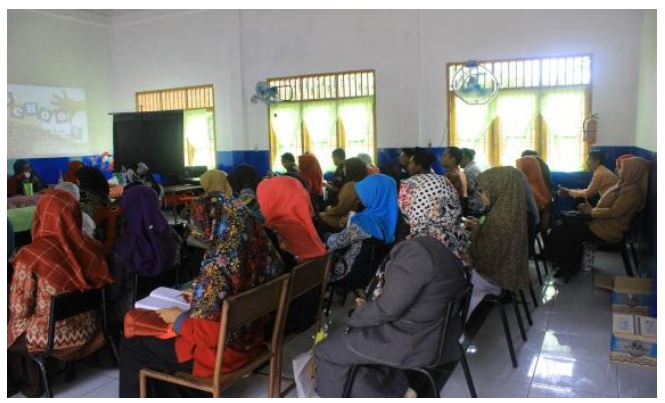

Gambar 1 Guru-Guru Yayasan Perguruan Alma'shum

\subsection{Media Pembelajaran Interaktif}

Menurut Dimyati dan Mujiono (1999) dalam Komara (2014) Pembelajaran Interaktif adalah suatu kegiatan guru yang secara terprogram dalam desain instruksional, untuk membuat siswa belajar secara aktif yang menekankan pada penyediaan sumber belajar. Ditambahkannya pula, model pembelajaran interaktif adalah suatu cara atau teknik pembelajaran yang digunakan oleh guru/fasilitator pada saat menyajikan bahan pelajaran dimana guru pemeran utama dalam menciptakan situasi interaktif yang edukatif, yakni interaksi antara guru dengan siswa, siswa dengan siswa dan dengan sumber pembelajaran dalam menunjang tercapainya tujuan belajar

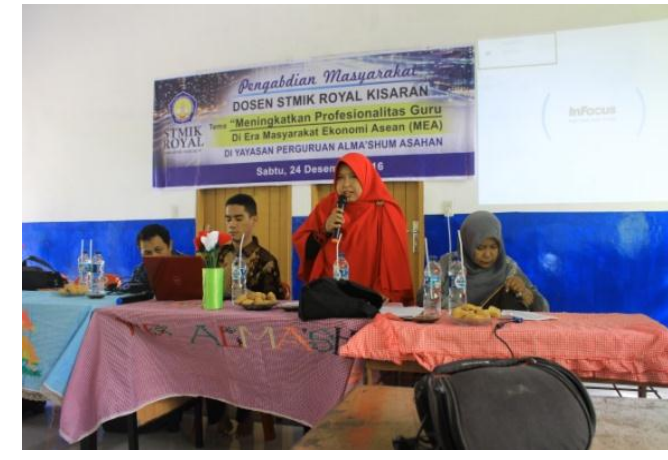

Gambar 2 Penjelasan Materi oleh Tim

Dosen

Syarat model pembelajaran interaktif dikemukakan oleh Ahmad Sabri dalam Endang Komara (2014) adalah sebagai berikut: (1) dapat membangkitkan motivasi, minat atau gairah belajar siswa, (2) dapat merangsang keinginan siswa untuk belajar lebih lanjut, (3) dapat memberikan kesempatan bagi siswa untuk memberikan tanggapannya terhadap materi yang disampaikan, (4) dapat menjamin perkembangan kegiatan kepribadian siswa, (5) dapat mendidik siswa dalam teknik belajar sendiri dan cara memperoeh pengetahuan melalui usaha pribadi, (6) dapat menanamkan dan mengembangkan nilai-nilai dan sikap siswa dalam kehidupan sehari-hari. (Sabri dalam Endang Komara, 2014)

a. Langkah-Langkah Membuat Media Pemelajaran Interaktif

Lima langkah dalam pembuatan media Interaktif adalah: (Course Training Web, Langkah 1 Menyiapkan File - Jalankan aplikasi PowerPoint (Start > All Programs > Microsoft Office > Microsoft Office PowerPoint 2007)

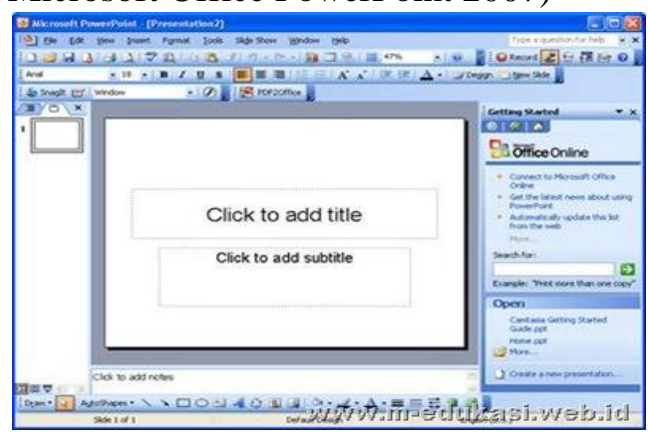

Gambar 3 Tampilan Microsoft Power Point

a. Klik menu File lalu pilih Save as 
Vol. 1, No. 2, Jul 2018, hlm. 69 - 74

Available online at http://jurnal.stmikroyal.ac.id/index.php/jurdimas

b. Di bagian file name, tulis nama file, dan kemudian klik tombol Save.

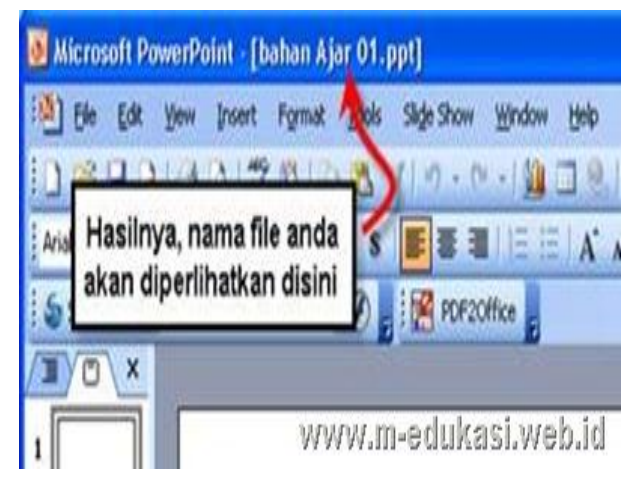

Gambar 4 Tampilan hasil

1. Langkah 2 Menyiapkan Slide

Berikut langkah-langkah menyiapkan

slide bahan ajar interaktif:

1. Jalankan Microsoft Power Point

2. Pilih layout Title Only.

3. Klik Slide Show > Set Up Show

4. Pilih opsi Browsed at a kios (full screen), lalu klik OK.

4. Salin Slide 1 sebanyak kebutuhan. Misalnya diperlukan

5. Berikan judul pada tiap-tiap slide

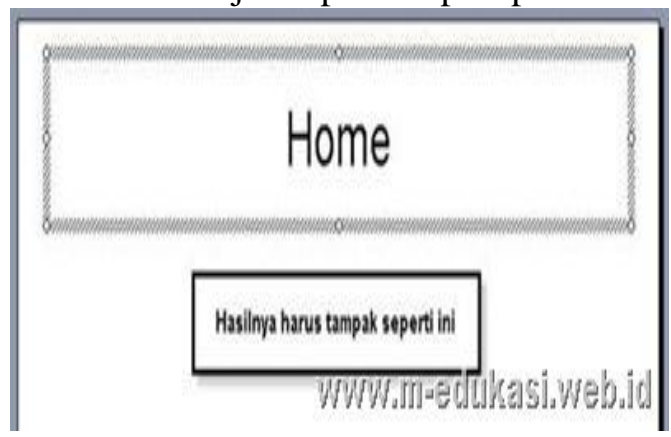

Gambar 5 Tampilan Hasil

2. Langkah 3 Menyiapkan Tombol

Tombol diperlukan sebagai navigasi menuju ke bagian-bagian lain dalam bahan ajar interaktif anda. Power Point menyediakan Toolbar Drawing untuk keperluan menggambar obyek.
a. Pastikan bahwa anda sedang berada di Slide 1
b. Klik Auto Shapes > Basic Shapes > Rounded Rectangle.
c. Drag didalam slide sehingga terbentuk bangun persegi-panjang.
d. Mengatur-ulang bentuk obyek
e. Menerapkan efek isian (fill effect)

f. Penambahan teks

Klik-kanan tepat pada obyek tombol

1. Pilih menu Add Text

2. Ketik teks Home

3. Bila diperlukan, berilah efek cetak tebal (Bold) dan efek bayangan (Shadow) terhadap teks itu.

4. Klik diluar obyek tombol

g. Penyalinan obyek

1. Pilih obyek tombol

2. Klik icon Copy pada toolbar

3. standard, lalu klik icon Paste

4. Buatlah 5 buah salinan (klik icon Paste sebanyak 5 kali)

h. Penempatan Objek Tombol

4. Langkah 4: Menyisipkan Hyperlink Hyperlink adalah suatu koneksi dari satu slide ke slide lain, halaman web, file, atau custom show. Hyperlnk itu sendiri dapat berupa teks, obyek atau WordArt.

1. Pilih tombol Home.

2. Klik icon Insert Hyperlink pada toolbar standard

3. Di bagian Link to, pilih Place in This Document

4. Di bagian Select a place in this document, pilih slide Home

5. Klik OK

6. Ulangi langkah (1) hingga (5)

7. untuk menyisipkan hyperlink ke tombol-tombol lainnya sehingga setiap tombol mengkait ke slideslide yang bersesuaian.

8. Menyisipkan efek animasi Guna mendukung kesan realistik pada tombol yang sudah dibentuk oleh efek isian (fill effect), perlu diberikan pula efek animasi.
a. Pilih tombol Home
b. Klik menu Slide Show, lalu pilih Action Setting...
c. Pastikan tab Mouse Click dalam keadaan terpilih.
d. Klik opsi Highlight click
e. Klik tab Mouse Over
f. Klik opsi Highlight when mouse over
g. Klik OK 
Vol. 1, No. 2, Jul 2018, hlm. 69 - 74

Available online at http://jurnal.stmikroyal.ac.id/index.php/jurdimas

5. Langkah 5 Pengaturan Navigasi

a. Menyalin tombol-tombol navigasi ke setiap slide

1. Pilih seluruh tombol pada Slide Home..

2. Klik icon Copy pada toolbar standard

3. Pilih Slide Author, lalu klik icon paste

4. Pilih slide $\mathrm{SK} / \mathrm{KD}$, lalu klik icon Paste

5. Pilih Slide Indikator, lalu klik icon Paste

6. Pilih Slide Materi, lalu klik icon Paste

7. Pilih Slide Evaluasi, lalu klik icon Paste Sekarang, seluruh slide sudah dilengkapi dengan tombol navigasi.

b. Penyesuaian hyperlink

1. Pilih tombol Home didalam Slide Home

2. Klik icon Insert Hyperlink pada toolbar standard

3. Klik tab Mouse Click (jika belum terbuka)

4. Pilih opsi None

5. Uncheck opsi Highlight click

6. Klik tab Mouse Over

7. Uncheck opsi Highlight when mouse over

8. Klik OK

9. Pilih tombol Home (didalam slide Home)

10. Klik icon Fill Color pada toolbar Drawing

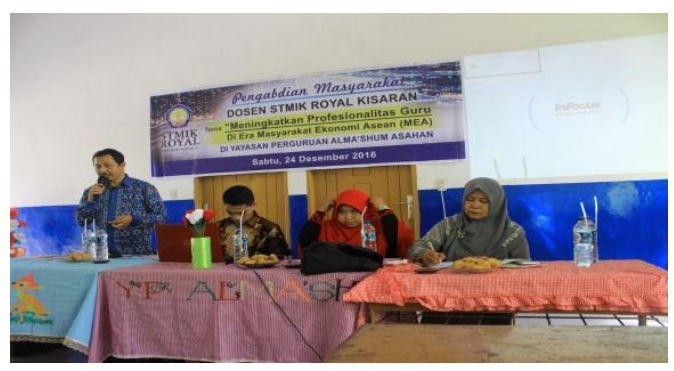

Gambar 6 Penjelasan materi Pembelajaran Interaktif oleh Tim Dosen

Kegiatan pengabdian kepada masyarakat ini tentunya, tak terlepas dari bantuan berbagai pihak, untuk itu ucapan terima kasih kami sampaikan kepada:

1. Bapak Anda Putra Lubis, SE., MMA, Ketua Yayasan Royal Teladan Asahan, sebagai penyandang dana,

2. Bapak Noto adi Luwih sebagai Ketua Yayasan perguruan Alma'shum beserta seluruh panitia dan guru-guru Perguruan Alma'shum

3. Tim pengabdian kepada masyarakat yang telah bekerjasama dengan baik, sehingga kegiatan dapat berjalan lancar dan sukses.

\section{DAFTAR PUSTAKA}

Komara E., 2014. Belajar dan Pembelajaran Interaktif, Bandung: PT Refika Aditama.

Mugara, Ronny. 2011. Meningkatkan Kompetensi Guru melalui Penguasaan TeknologiInformasi dan Komunikasi (TIK)

Muchith, M. Sackhan. 2008. Pembelajaran Kontekstual. Semarang: Rasail Media Grup.

Surya, Mohamad. 2013. Psikologi Guru. Bandung: STKIP Garut Press.

Utari Unga, I Nyoman Sudana Degeng, Sa'dun Akbar.2016 Pembelajaran Tematik Berbasis Kearifan Lokal Di Sekolah Dasar Dalam Menghadapi Masyarakat Ekonomi Asean (MEA) Jurnal Teori dan Praktis Pembelajaran IPS Vol.1 No.1 April 2016 